\title{
Employment experience in relation to alcohol, tobacco, and betel nut use among youth in Taiwan
}

\author{
Chuan-Yu Chen ${ }^{\mathrm{a}}$, Wen-Chun Chen ${ }^{\mathrm{b}}$, Chih-Yin Lew-Ting ${ }^{\mathrm{c}}$, Ching-Mei Lee ${ }^{\mathrm{d}}$, \\ Cheng-Fang Yen ${ }^{\mathrm{e}}$, Duan-Rung Chen ${ }^{\mathrm{f}}$, Chuhsing Kate Hsiao ${ }^{\mathrm{b}}$, \\ Chaucer C.H. Lin ${ }^{\mathrm{g}}$, Ming-Jen Yang ${ }^{\mathrm{e}}$, Te-Jen Lai ${ }^{\mathrm{h}}$, Wei J. Chen ${ }^{\mathrm{b}, \mathrm{i}, *}$ \\ ${ }^{a}$ Division of Mental Health and Substance Abuse Research, National Health Research Institutes, Taipei, Taiwan \\ ${ }^{\mathrm{b}}$ Institute of Epidemiology, College of Public Health, National Taiwan University, Taipei, Taiwan \\ ${ }^{\mathrm{c}}$ Institute of Health Policy and Management, College of Public Health, National Taiwan University, Taipei, Taiwan \\ ${ }^{\mathrm{d}}$ Department of Health Education, National Taiwan Normal University, Taipei, Taiwan \\ ${ }^{\mathrm{e}}$ Department of Psychiatry, College of Medicine and Kaohsiung Medical University Chong-Ho Memorial Hospital, \\ Kaohsiung Medical University, Kaohsiung, Taiwan \\ ${ }^{\mathrm{f}}$ Institute of Health Care Administration, College of Public Health, National Taiwan University, Taipei, Taiwan \\ ${ }^{g}$ Department of Psychiatry, Buddhist Tzu-Chi General Hospital, Hualien, Taiwan \\ ${ }^{\mathrm{h}}$ Department of Psychiatry and Institute of Medicine, Chung Shan Medical University, Taichung, Taiwan \\ ${ }^{\mathrm{i}}$ Department of Psychiatry, College of Medicine and National Taiwan University Hospital, National Taiwan University, Taipei, Taiwan
}

Received 22 November 2005; received in revised form 13 February 2006; accepted 4 March 2006

\begin{abstract}
The aim of this study is to assess the association linking employment experience with alcohol, tobacco, and betel nut involvement among youth in Taiwan. In 2004, an outreach program was conducted during weekdays to recruit youth sample in seven major geographic regions. A total of 5886 youth aged 12-18 years drawn from 26 cities or towns were assessed by a two-page anonymous self-administered questionnaire, including sociodemographic characteristics, employment-, development-, and drug-related experiences. In Taiwan, youthful experience of alcohol, tobacco, and polydrug use varies by employment status, work intensity, and job type. Holding a full-time job and working in certain settings (e.g., grocery, restaurants) were found associated with an excess of drug-using behaviors. With taking age, male gender, family context, disposable allowance, and school attendance into account, working youths were two to four times as likely to have recent drug involvement than their non-working counterparts, especially for tobacco and polydrug ( $\mathrm{OR}=3.32,95 \% \mathrm{CI}: 2.58-4.27, p<0.001 ; \mathrm{OR}=3.76,95 \% \mathrm{CI}: 2.76-5.13, p<0.001)$. Youths in the labor force emerge as a subgroup experiencing greater use of alcohol, tobacco, betel nut, and polydrug. Future prevention programs may target this high-risk group to reduce possible drug-related negative consequences in developmental and health domains in Taiwan.
\end{abstract}

(C) 2006 Elsevier Ireland Ltd. All rights reserved.

Keywords: Employment; Adolescents; Tobacco; Alcohol; Betel nut; Outreach program

\section{Introduction}

Adolescents in the labor force have been found to experience disproportionately higher rates of health and behavior-related problems, including alcohol, tobacco, and illegal drug involvement (Johnson, 2004; Kouvonen and Lintonen, 2002; Mortimer et al., 1996; Paschall et al., 2002, 2004; Valois et al., 1999; Wu et al., 2003). Several hypotheses or mechanisms have been

\footnotetext{
* Corresponding author. Tel.: +8862 2312 3456x8360; fax: +886223560840. E-mail address: weijen@ha.mc.ntu.edu.tw (W.J. Chen).
}

proposed to explain the connection between adolescent employment and psychoactive drug use, such as differential selection, precocious development, and differential association theory (see Finch et al., 1997; McMorris and Uggen, 2000). For instance, Bachman and Schulenberg (1993), among others (Sanford et al., 1994), suggested that the greater risk of psychoactive drugrelated problems among working youth might be explained by distant factors which led to both earlier entry into the labor force and subsequent engagement in drug-related activities, such as disadvantaged family background (e.g., low-income or lower parental education), unfavorable family structure (e.g., singleparent family), or school problems (e.g., unsatisfactory grade, 
school truancy). Nevertheless, longitudinal evidence derived from about 1000 high school attendants found that work alone might still have its independent influences on youngsters' drinking behaviors, operating via exposing them to opportunities or associates that facilitate alcohol use (McMorris and Uggen, 2000). In addition, youths with longer hours of work seem to spend more time in unstructured social activities, which were associated with increased risks of drug exposure opportunity and initiation (Chen et al., 2004; Osgood et al., 1996; Safron et al., 2001).

In the past decade, tobacco and alcohol use-related problems in youth population have emerged as important public health issue in many developing countries. In Taiwan, after the opening of the tobacco and alcohol markets to foreign imports (Hsu et al., 2005), the National Health Surveys have shown that the median onset age of cigarette smoking has continuously declined in younger cohorts, and smoking rates have been noticeably elevated among young adults, particularly for females (Wen et al., 2005a). Intriguingly, web-based self-administered surveys of high school students suggested that the lifetime prevalence estimates for alcohol, tobacco, and betel nut were 38.3, 21.3, and $6.1 \%$, respectively, nearly $1.2-1.5$ times greater than the corresponding estimates derived from self-administered paperand-pencil questionnaires (Wang et al., 2005). In the meantime, betel nut, one of the widely consumed psychoactive substance in Asian countries, has gradually caught local public health professionals' attention due to observed compulsive chewing behaviors and increased risks of oral cavity cancer among betel nut users (Chu, 2001). In Taiwan, betel nut is usually chewed with the leaves of betel pepper and lime, and the majority of betel nut chewers were cigarette smokers as well. The prevalence rate of betel nut use has been reported as high as 50\% among aboriginal youths (Tsai et al., 2002), and the age of first betel nut appears later than that of cigarette (Wen et al., 2005b).

Compulsory education in Taiwan takes the form of a 6-year primary education and 3-year junior secondary education for youngsters aged 6-15 years. The legal minimum age of employment is 15 years, even though having a part-time or seasonal work is not uncommon among youth under the age of 15 years. Less attention has been paid to work conditions, benefits, and risks of underage workers until recent years, and it was estimated that one out of two to three youths aged 15-19 have ever worked in the preceding year (National Statistics, 2005). Some evolving trend has also been noted in relation to the characteristics of growing working population among students, such as "personal allowance" has replaced "supporting family" as the main reason for youth to seek jobs, and the majority of job type has shifted from labor-oriented to service-oriented. Taken together, in the context of growing availability of psychoactive substance, it is important to probe into whether such changes in the profile of teenage labor force is associated with an increase in substance use among youth population.

The purpose of this study is to examine the extent to which adolescent employment was associated with alcohol, tobacco, and betel nut use in Taiwan. With few exception (Wakai et al., 2005), prior evidence on employment and drug involvement has been mainly derived from the Western societies (Kouvonen and
Lintonen, 2002; McMorris and Uggen, 2000; Paschall et al., 2004), and it is not clear whether such youthful employmentrelated problems will be observed in other societies with different drug availability and education/employment opportunity. Building upon a large sample derived from a street outreach program in Taiwan, which was designed to recruit youth with diverse lifestyle in the cities or towns (not exclusively limited to the homeless or school dropouts), we sought to assess the strength of associations linking employment-related experiences with three most commonly consumed drugs-alcohol, tobacco, and betel nut, with adjustment for possible differential background characteristics.

\section{Methods}

\subsection{Study population}

The data for this study were derived from a street outreach program designed to investigate health and drug-using behaviors among youth in Taiwan. Between August 2004 and November 2004 (covering the last month of summer recess and the first three months of academic year 2004), the multistage sampling approach was adapted in effort to obtain youth respondents with national representativeness. On the basis of geographic characteristics, urbanicity level, and population composition, Taiwan was first partitioned into seven main geographic clusters, and several major cities/towns within each cluster were then drawn to implement this outreach project. A total of 26 cities/towns were selected to carry out subject recruitment. Building upon the field work carried out by experienced social workers in the pilot study (Chou et al., 2006), the outreach survey was conducted in the selected natural settings known commonly frequented by teenagers in Taiwan (e.g., fast food restaurants, pool halls, internet cafés, shopping malls, bookstores, train stations, and so on), with an intention to recruit respondents in their communities, rather than in school settings or clinics. Subjects were sampled/approached on the basis of their appearance of being a teenager. Each outreach team was composed of two to three trained interviewers who were primarily in charge of sampling respondents, keeping track of refusals' information (i.e., gender), and collecting data. No more than 30 individuals per selected sampling site were assessed on any given day, and the recruitment period was limited-between 4:00 and 10:00 p.m. each weekday, in order to sample youths with diverse personal backgrounds and lifestyle.

Overall response rate for outreach survey was $75.7 \%$, and the region-specific rates ranged from 65.9 to $83.5 \%$. Male youths were more likely to refuse participation in comparison with their female counterparts (26.1\% versus $22.7 \%$ ). Detailed information with respect to sampling procedures and research assessment can also be obtained elsewhere (Chou et al., 2006). The study was reviewed and approved by the Institutional Review Board of College of Public Health, National Taiwan University.

\subsection{Measures}

All the participants were assured of anonymity and confidentiality before obtaining signed informed consents in the form of undisclosed identity (e.g., nickname or fake name). The data were then collected via a self-administered paper-and-pencil questionnaire that took approximately $10-15 \mathrm{~min}$ to complete. Standardized survey questions inquired about personal background, development-related characteristics, health behaviors, and drug experiences. Participants received stationery incentives in the price of no more than $20 \mathrm{New}$ Taiwan Dollars (NTD) from the outreach program as the assessment completed (US\$ $1 \cong 30$ NTD).

Lifetime drug experiences, including ever use, the age and circumstance at first use, motive for first use, average frequency of consumption, cumulative frequency, and recency of use, were assessed with respect to fourteen types of psychoactive substance: alcohol, tobacco, betel nut, diet food, energy drinks, and nine types of illegal drugs. Given that diet-related medications or drugs (e.g., amphetamines) have oftentimes been found in many forms of edibles in Taiwan, 
the present study used "diet food" as a category covering a wide range of dietrelated food, pills, and supplements. Recent drug experiences were assessed on the basis of questions asking recency of use, and the value of ' 1 ' was assigned when the youth reported having used such drug on at least one occasion during the 30 days prior to the time of the outreach interview. Recent polydrug use was defined on the basis of three most commonly consumed psychoactive drugs in Taiwan—alcohol, tobacco, and betel nut. Onset age for each drug was coded as a continuous variable.

Four questions were adapted to assess working experience, including employment status, worksite, job title, and wage, such as "Are you currently employed in a full-time or part-time job?" Owing to only 48 participants working full-time $(0.8 \%)$, we then decided to combine "full-time employment" and "part-time employment $(n=623$ and 10.6\%)" into one category- -working youth." According to the reported worksite and job type, employed youths were subsequently regrouped into four main categories of job type: "Grocery or convenient stores $(n=113)$," "Restaurant, or food and beverage services $(n=166)$," "Educational support personnel (e.g., clericals; $n=77)$," "Others (e.g., factory technicians, automobile mechanics, gas station attendants, packing, or wrapping workers; $n=199)$," and "Unknown or notspecified $(n=116)$." Several factors thought possibly associated with employment and drug use in this study include age, gender, family structure (e.g., currently inhabiting with family, single-parent family), weekly allowance, and school attendance. Youthful weekly disposable allowance, a proxy measure for family socioeconomic status (Soteriades and DiFranza, 2003), was assessed by a six-response category, ranging from " 0 NTD" to "2001 or above NTD”.

Table 1

Sample characteristics of youth by working status in the 2004 outreach program, Taiwan

\begin{tabular}{|c|c|c|c|}
\hline Variables & Non-working youth, $n(\%)$ & Working youth, $n(\%)$ & Crude, OR $^{\mathrm{a}} 95 \% \mathrm{CI}$ \\
\hline Total & $5215(100.0)$ & $671(100.0)$ & \\
\hline \multicolumn{4}{|l|}{ Age (years) } \\
\hline $12-15$ & $2522(48.4)$ & $186(23.7)$ & 1.00 \\
\hline $16-18$ & $2693(51.6)$ & $485(72.3)$ & $2.44(1.8-3.4)^{* * *}$ \\
\hline \multicolumn{4}{|l|}{ Gender } \\
\hline Female & $2880(55.2)$ & $380(56.6)$ & 1.00 \\
\hline Male & $2335(44.8)$ & $291(43.4)$ & $0.94(0.8-1.1)$ \\
\hline \multicolumn{4}{|l|}{ Family structure } \\
\hline Both parents & $4558(87.4)$ & $510(76.0)$ & 1.00 \\
\hline Single parent & $657(12.6)$ & $161(24.0)$ & $2.19(1.9-2.5)^{* * *}$ \\
\hline \multicolumn{4}{|l|}{ Living with family } \\
\hline Yes & $4887(93.7)$ & $590(87.9)$ & 1.00 \\
\hline No & $328(6.3)$ & $81(12.1)$ & $2.05(1.5-2.9)^{* * *}$ \\
\hline \multicolumn{4}{|l|}{ Attending school } \\
\hline Yes & $5176(99.2)$ & $638(95.1)$ & 1.00 \\
\hline No & $39(0.8)$ & $33(4.9)$ & $6.86(5.1-9.3)^{* * *}$ \\
\hline \multicolumn{4}{|c|}{ Disposable allowance $\left(\mathrm{NTD}^{\mathrm{b}}\right.$ per week) } \\
\hline $0-500$ & $2710(52.0)$ & $379(56.5)$ & 1.00 \\
\hline $501-1500$ & $2057(39.4)$ & $232(34.5)$ & $0.81(0.7-1.0)^{*}$ \\
\hline 1501 or above & $448(8.6)$ & $60(9.0)$ & $0.96(0.7-1.3)$ \\
\hline \multicolumn{4}{|l|}{ Lifetime drug-related experiences ${ }^{\mathrm{c}}$} \\
\hline \multicolumn{4}{|l|}{ Alcohol use } \\
\hline Never & $3558(68.2)$ & $332(49.5)$ & 1.00 \\
\hline Ever & $1657(31.8)$ & $339(50.5)$ & $1.93(1.5-2.4)^{* * *}$ \\
\hline \multicolumn{4}{|l|}{ Tobacco use } \\
\hline Never & $4465(85.6)$ & $458(68.3)$ & 1.00 \\
\hline Ever & $750(14.4)$ & $213(31.7)$ & $2.65(2.2-3.2)^{* * *}$ \\
\hline \multicolumn{4}{|l|}{ Betel nut use } \\
\hline Never & $5076(97.3)$ & $620(92.4)$ & 1.00 \\
\hline Ever & $139(2.7)$ & $51(7.6)$ & $2.81(2.0-4.0)^{* * *}$ \\
\hline \multicolumn{4}{|l|}{ Illegal drug use } \\
\hline Never & $5139(98.5)$ & $643(95.8)$ & 1.00 \\
\hline \multirow[t]{2}{*}{ Ever } & $76(1.5)$ & $28(4.2)$ & $2.77(1.8-4.2)^{* * *}$ \\
\hline & Mean (S.E.) & Mean (S.E.) & $95 \% \mathrm{CI}\left(P^{\mathrm{d}}\right)$ \\
\hline Mean age of alcohol initiation & $13.3(0.07)$ & $13.7(0.17)$ & $-0.16,0.25(0.60)$ \\
\hline Mean age of tobacco initiation & $12.9(0.09)$ & $13.6(0.15)$ & $0.25,0.75(0.006)$ \\
\hline Mean age of betel nut initiation & $13.2(0.26)$ & $13.6(0.32)$ & $-0.83,1.43(0.54)$ \\
\hline
\end{tabular}

${ }^{a}$ Estimates obtained from a logistic regression model taking region clustering design effects into account.

b New Taiwan Dollars (1 US\$ $\cong 30$ NTD).

c Estimates obtained from a logistic regression model taking region clustering design effects into account and with adjustment for age.

$\mathrm{d}$ Estimates obtained from a linear regression model taking region clustering design effects into account and with adjustment for age.

* $P<0.05$.

*** $P<0.001$. 


\subsection{Data analysis}

Contingency table analyses were first performed to examine whether the distribution of personal characteristics and lifetime drug experiences differed by current working status. Next, age-adjusted association linking employment and alcohol, tobacco, betel nut, and illegal drug involvement were estimated via logistic regression models. Possible employment-related differences in the age of drug initiation were also probed by linear regression models. Given that youth within the same region would be more likely to be similar to each other than those living in other regions, we decided to analyze region as a cluster unit to take into account possible effects of intra-region interdependence on the association estimates (i.e., standard errors). Although a considerable proportion of participants had tried illegal drugs prior to the interview ( $n=104$ and $1.8 \%$ ), few of them had illegal drugs within the 30 days preceding the outreach assessment ( $n=31$ and $0.53 \%)$. Therefore, the present analyses were opted to focus on recent use of alcohol, tobacco, and betel nut, in an attempt to acquire more precise estimates.

Multivariate logistic and multinomial (polytomous) logistic regression analyses were carried out to estimate the strength of associations linking employment-related experiences with recent drug involvement, with or without adjustment for other covariate. On the basis of three employment measures, that is, employment, work intensity (full-time versus part-time), and job type, our multivariate regression analyses involved three models, and the results are presented in the form of odds ratios (OR) and 95\% confidence intervals (CIs). All the analyses were conducted using the STATA software package (StataCorp, 2003).

\section{Results}

A total of 6014 participants completed the survey questionnaire. The present study focused on the 5886 youth who were 12-18 years old at the time of the interview and who had valid data with respect to variables of major interest; 123 participants whose ages were under 12 or above 18 , as well as 5 participants who reported use of a fake drug were excluded.

An estimated $11.4 \%$ of the youth in our sample were employed at the time of assessment $(n=671)$. Differences between working and non-working youth pertaining to personal and family characteristics are summarized in Table 1. Working youths tended to have an older age, come from a single-parent family, not living with family, not attending school, and have less disposable allowance, but there seems to be no differences in relation to gender. For example, the odds of not attending school for working youth were about six- to seven-fold greater than their non-working counterparts (95\% CI: $5.1-9.3, p<0.001)$. As to lifetime drug involvement, the likelihood for alcohol, tobacco, betel nut, and illegal drug experiences were consistently greater among working youths $(\mathrm{OR}=1.9-2.8)$. The average onset age of alcohol and betel nut did not vary by employment status; however, working youth generally reported to start tobacco use at an older age as compared to their non-working smoking peers $(p=0.006)$.

An estimated $12.7,6.8$, and $1.1 \%$ of participating youths have consumed alcohol, tobacco, and betel nut in the past month, respectively. Among 932 youths who reported using any of alcohol, tobacco, or betel nut recently (15.8\%), 696 were users of one drug only $(11.8 \%)$. The remaining 236 youths were those who had co-occurring use of two or more legal psychoactive drugs, including 41 users of alcohol, tobacco, and betel nut. Mindful of the scarcity for users of betel nut only $(n=1)$ and users of all three drugs $(n=41)$, youthful participants were then classi-

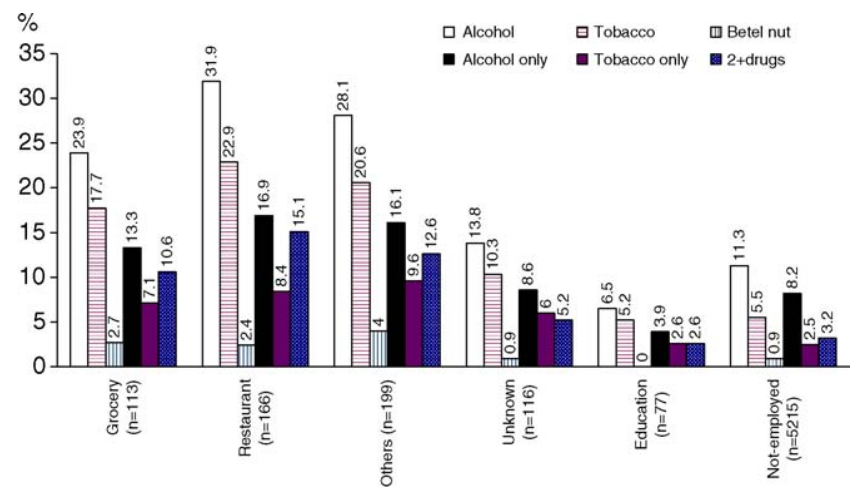

Fig. 1. Recent use of alcohol, tobacco, and betel nut among youth in the street outreach program, by job type, Taiwan 2004.

fied by drug type and single/poly drug use. The distribution of recent alcohol, tobacco, and betel nut experiences in relation to job type is depicted in Fig. 1. In general, higher rates of recent drug involvement were more likely to be found among youths working in grocery, restaurants or food-and-drinks services, and "other" category, regardless of drug type and polydrug use status. For instance, roughly one in three respondents who were working in restaurants had drank alcohol on at least one occasion in the past month $(31.9 \%)$, and the corresponding estimate for polydrug use was approximately $15 \%$. On the other hand, the rates of drug experiences among youth currently holding a job in educational settings, such as schools and cram schools-specialized private schools that train students to meet particular goals (e.g., passing the entrance examination), were consistently lower than their non-employed peers. An estimated 2-3\% of youths hired in educational setting had used two or more drugs recently, and none has chewed betel nut in the month prior to the interview.

The estimated drug-specific odds ratios between working status and recent drug experience (i.e., past month) are summarized in Table 2. Adolescents who were male, raised by a single-parent, not attending school, and having greater disposable allowance were found to be more likely to engage in alcohol-, or tobacco-related behaviors in the 30 days prior to the interview. Having a job was associated with an increased two to three fold odds of recent alcohol, tobacco, and betel nut use, regardless of youth's age, gender, and family structure. In general, the association estimates linking employment with alcohol and tobacco involvement did not have appreciable changes, after statistical adjustment for disposable allowance, living with family, and school attending status (Model 3-alcohol, $\mathrm{OR}=2.14$, 95\% CI: 1.59-2.87; tobacco, OR=3.32, 95\% CI: 2.58-4.27; betel nut, $\mathrm{OR}=1.98,95 \% \mathrm{CI}: 0.89-4.37$ ).

Table 3 shows the associations linking employment-related experiences with recent single or polydrug use. Consistent with the estimates in Table 2, having a job was associated with a greater likelihood of recent drug involvement, especially for polydrug use ( $\mathrm{OR}=4.00,95 \% \mathrm{CI}$ : 2.95-5.42). The increased odds of drug use were much greater for those who worked fulltime (tobacco only, $\mathrm{OR}=6.22,95 \% \mathrm{CI}$ : 2.42-16.0; at least two drugs, $\mathrm{OR}=10.6,95 \% \mathrm{CI}: 3.73-29.8)$. Youth reporting to be employed in job types such as grocery, restaurants and others were more likely to have used alcohol, tobacco, and two or more 
Table 2

Drug-specific associations between working status and recent drug experience among youth in the outreach program, Taiwan, 2004

\begin{tabular}{|c|c|c|c|}
\hline \multirow[t]{2}{*}{ Variables $^{\mathrm{a}, \mathrm{b}}$} & \multicolumn{3}{|c|}{ OR $(95 \% \mathrm{CI})$} \\
\hline & Alcohol & Tobacco & Betel nut \\
\hline \multicolumn{4}{|l|}{ Crude association } \\
\hline Having a job & $2.40(1.74-3.33)^{* * *}$ & $3.58(3.09-4.14)^{* * *}$ & $2.63(1.30-5.32)^{* *}$ \\
\hline \multicolumn{4}{|l|}{ Model 1} \\
\hline Having a job & $2.11(1.58-2.82)^{* * *}$ & $3.38(2.67-4.27)^{* * * *}$ & $2.20(1.02-4.71)^{*}$ \\
\hline Older age (16-18 vs. $12-15)$ & $1.66(1.35-2.05)^{* * *}$ & $1.10(0.68-1.76)$ & $1.50(0.63-3.57)$ \\
\hline Male & $1.32(1.17-1.49)^{* * *}$ & $2.88(2.29-3.60)^{* * *}$ & $4.56(2.62-7.94)^{* * *}$ \\
\hline Single parent family & $1.43(1.27-1.60)^{* * *}$ & $1.97(1.54-2.52)^{* * *}$ & $2.24(1.42-3.56)^{* * *}$ \\
\hline \multicolumn{4}{|l|}{ Model 2} \\
\hline Having a job & $2.19(1.65-2.91)^{* * *}$ & $3.53(2.84-4.40)^{* * *}$ & $2.26(1.08-4.74)^{*}$ \\
\hline Older age (16-18 vs. $12-15)$ & $1.53(1.25-1.86)^{* * * *}$ & $1.01(0.67-1.50)$ & $1.43(0.64-3.16)$ \\
\hline Male & $1.28(1.13-1.45)^{* * *}$ & $2.83(2.31-3.48)^{* * * *}$ & $4.53(2.61-7.85)^{* * * *}$ \\
\hline Single parent family & $1.40(1.23-1.60)^{* * *}$ & $1.95(1.52-2.50)^{* * *}$ & $2.24(1.41-3.54)^{* * * *}$ \\
\hline \multicolumn{4}{|c|}{ Disposable allowance (ref: 0-500 NTD) } \\
\hline $501-1500$ & $1.32(1.06-1.63)^{* *}$ & $1.49(1.14-1.96)^{* *}$ & $1.30(0.75-2.25)$ \\
\hline 1501 or above & $1.97(1.36-2.86)^{* * *}$ & $1.49(0.79-2.82)$ & $1.15(0.80-1.67)$ \\
\hline \multicolumn{4}{|l|}{ Model 3} \\
\hline Having a job & $2.14(1.59-2.87)^{* * *}$ & $3.32(2.58-4.27)^{* * *}$ & $1.98(0.89-4.37)$ \\
\hline Older age (16-18 vs. $12-15)$ & $1.51(1.23-1.85)^{* * *}$ & $1.00(0.66-1.50)$ & $1.43(0.64-3.23)$ \\
\hline Male & $1.28(1.13-1.44)^{* * *}$ & $2.78(2.25-3.43)^{* * * *}$ & $4.35(2.52-7.50)^{* * *}$ \\
\hline Single parent family & $1.39(1.23-1.56)^{* * *}$ & $1.92(1.49-2.48)^{* * * *}$ & $2.19(1.38-3.47)^{* * * *}$ \\
\hline \multicolumn{4}{|c|}{ Disposable allowance (ref: 0-500 NTD) } \\
\hline $501-1500$ & $1.31(1.06-1.62)^{* *}$ & $1.54(1.21-1.96)^{* * * *}$ & $1.39(0.80-2.43)$ \\
\hline 1501 or above & $1.92(1.31-2.81)^{* * *}$ & $1.55(0.83-2.87)$ & $1.29(0.86-2.43)$ \\
\hline Not living with family & $1.23(0.97-1.58)$ & $0.94(0.70-1.26)$ & $0.61(0.29-1.27)$ \\
\hline School non-attendance & $1.47(0.69-3.11)$ & $3.73(1.18-11.8)^{*}$ & $5.43(2.03-14.5)^{* * * *}$ \\
\hline
\end{tabular}

New Taiwan Dollars (US\$1 $\cong 30$ NTD).

${ }^{a}$ Estimates obtained from a logistic regression model taking region clustering design effects into account and with adjustment for other covariates listed under the model.

${ }^{b}$ Reference group: non-current users, including drug-naïve.

${ }^{*} P<0.05$.

** $P<0.01$

*** $P<0.001$.

drugs recently, whereas a lower odds of recent drug experience was observed among youths holding a job in educational settings, but no statistical differences were detected (e.g., alcohol, OR $=0.45,95 \%$ CI: $0.15-1.31$ ).

In general, after statistical adjustment for age, male gender, being raised by single-parent family, weekly disposable allowance, living with family, and school attendance status, the association estimates linking employment-related experiences with recent drug involvement did not show appreciable changes. Based on the estimates of adjusted odds ratios in the lower panel of Table 3, summarizing over all employment-related experiences, the odds of drug involvement for working youths were about two to four times greater than that for non-working ones, especially for those who were employed in grocery, restaurants, and others (e.g., at least two drugs for restaurants, $\mathrm{OR}=6.56$, 95\% CI: 4.12-10.4).

Finally, to eliminate concern about possible confounding regional effects, we repeated a set of subsidiary Models 1-3 analyses, with statistical adjustment for regional variation. Using the same reference group (i.e., those who were not in the labor force), the working youths' adjusted odds ratios of "alcohol only," "tobacco only," and "at least two drugs" were 1.78 (95\%
CI: 1.24-2.55), 3.27 (95\% CI: 1.93-5.52), and 3.93 (95\% CI: 2.94-5.25), respectively. There were no appreciable changes in the resulting odds ratio estimates for work intensity and job type (data not shown in a table).

\section{Discussion}

In this study, we investigated the link between employment with alcohol, tobacco, and betel nut use behaviors in a sample of 5886 youth aged $12-18$ recruited by the outreach program in Taiwan, 2004. Our findings revealed that working youth seem more likely to have certain psychosocial characteristics associated with substance use, e.g., being raised by a singleparent, and having less bonds with conventional institutions. The employment-associated risks for psychoactive drug involvement were found across alcohol, tobacco, betel nut, and polydrug use in Taiwan, and the observed association was markedly stronger for the youths employed in the settings like grocery stores or restaurants.

Some potential limitations of this study should be considered before further discussion. One is that research subjects were recruited primarily from the outreach program, and as such, 
Table 3

The estimated associations between employment-related experiences and recent single/polydrug use among youth in the outreach program, Taiwan, 2004

\begin{tabular}{|c|c|c|c|}
\hline \multirow[t]{2}{*}{ Variables $^{\mathrm{a}, \mathrm{b}}$} & \multicolumn{3}{|c|}{ OR $(95 \% \mathrm{CI})$} \\
\hline & Alcohol only $(n=516)$ & Tobacco only $(n=179)$ & At least two drugs $(n=236)^{\mathrm{c}}$ \\
\hline \multicolumn{4}{|l|}{ Univariate model $^{\mathrm{d}}$} \\
\hline Having a job (full-time or part-time) & $1.98(1.34-2.96)^{* * *}$ & $3.75(2.62-5.36)^{* * *}$ & $4.00(2.95-5.42)^{* * * *}$ \\
\hline $\begin{array}{l}\text { Work intensity } \\
\text { Having a part-time job } \\
\text { Having a full-time job }\end{array}$ & $\begin{array}{l}2.02(1.35-3.03)^{* * *} \\
1.50(0.61-3.71)\end{array}$ & $\begin{array}{l}3.59(2.50-5.16)^{* * *} \\
6.22(2.42-16.0)^{* * * *}\end{array}$ & $\begin{array}{r}3.58(2.61-4.90)^{\text {**** }} \\
10.56(3.73-29.8)^{\text {**** }}\end{array}$ \\
\hline $\begin{array}{l}\text { Job type } \\
\text { Grocery } \\
\text { Restaurant } \\
\text { Educational setting } \\
\text { Other } \\
\text { Unknown }\end{array}$ & $\begin{array}{l}2.02(1.05-3.86)^{*} \\
2.97(1.60-5.50)^{* * *} \\
0.45(0.15-1.31) \\
2.71(1.72-4.26)^{* * *} \\
1.13(0.47-2.69)\end{array}$ & $\begin{array}{l}3.57(2.03-6.28)^{* * * *} \\
4.92(2.27-10.7)^{* * *} \\
0.99(0.26-3.76) \\
5.33(3.55-8.02)^{* * *} \\
2.62(1.02-6.75)^{*}\end{array}$ & $\begin{array}{l}4.14(3.10-5.53)^{* * *} \\
6.79(4.72-9.77)^{* * *} \\
0.77(0.10-6.09) \\
5.20(3.20-8.46)^{* * *} \\
1.73(0.55-5.42)\end{array}$ \\
\hline $\begin{array}{l}\text { Multivariate model } \\
\text { Model } 1 \\
\text { Having a job }{ }^{\mathrm{d}, \mathrm{e}}\end{array}$ & $1.75(1.21-2.53)^{* *}$ & $3.25(1.96-5.40)^{* * *}$ & $3.76(2.76-5.13)^{* * * *}$ \\
\hline $\begin{array}{l}\text { Model } 2^{\mathrm{d}, \mathrm{e}} \\
\text { Having a part-time job } \\
\text { Having a full-time job }\end{array}$ & $\begin{array}{l}1.78(1.23-2.58)^{* *} \\
1.25(0.48-3.23)\end{array}$ & $\begin{array}{l}3.31(2.01-5.46)^{* * *} \\
2.66(0.69-10.3)\end{array}$ & $\begin{array}{l}3.57(2.68-4.76)^{* * *} \\
6.16(1.56-24.3)^{* *}\end{array}$ \\
\hline $\begin{array}{l}\text { Model } 3^{\mathrm{d}, \mathrm{e}} \\
\text { Grocery } \\
\text { Restaurant } \\
\text { Educational setting } \\
\text { Other } \\
\text { Unknown }\end{array}$ & $\begin{array}{l}1.75(0.88-3.49)^{*} \\
2.55(1.45-4.47)^{* * *} \\
0.41(0.14-1.16) \\
2.45(1.49-4.04)^{* * *} \\
0.98(0.44-2.14)\end{array}$ & $\begin{array}{l}2.48(1.20-5.13)^{* * *} \\
4.61(1.89-11.2)^{\text {**** }} \\
1.06(0.27-4.22) \\
4.90(3.08-7.79)^{* * *} \\
2.08(0.60-7.24)^{*}\end{array}$ & $\begin{array}{l}3.28(2.00-5.39)^{* * * *} \\
6.56(4.12-10.4)^{* * *} \\
0.88(0.11-7.27) \\
5.02(2.85-8.86)^{* * *} \\
1.61(0.49-5.28)\end{array}$ \\
\hline $\begin{array}{l}\text { a Reference group: non-current users } \\
\text { b Estimates obtained from a multinom } \\
\text { c Include four different groups of drug } \\
\text { tobacco, and betel nut }(n=41) \text {. } \\
{ }^{\mathrm{d}} \text { Reference group: non-employed you } \\
{ }^{\mathrm{e}} \text { Estimates obtained from a multinon } \\
\text { single parent family, weekly disposable } \\
{ }^{*} P<0.05 \text {. } \\
{ }^{* *} P<0.01 . \\
{ }^{* * *} P<0.001 .\end{array}$ & $\begin{array}{l}\text { acco, and betel nut, inclu } \\
\text { ression model taking reg } \\
\text { alcohol and tobacco }(n= \\
\text { gression model taking re } \\
\text { living with family, and } \mathrm{n}\end{array}$ & $\begin{array}{l}\text { e }(n=4954) \text {. } \\
\text { design effects into accour } \\
\text { and betel nut }(n=7) \text {, alco } \\
\text { g design effects into acce } \\
\text { chool. }\end{array}$ & adjustment for age, male sex, \\
\hline
\end{tabular}

generalizability of the results to the youths in the general population in Taiwan and other places in the world may be at issue. The second drawback relates to the paper-and-pencil assessment, which was more likely to underestimate youthful drug-using behaviors. However, this underestimation may not have much influence on the associations of interest, due to that the underreported drug involvement was non-differential across subgroups defined by employment-related experiences. A similar limitation was also shown in male-related excess in participation refusal which may possibly be ignored given that employment experiences were almost equally distributed between males and females.

In addition, the lack of detailed information regarding employment (e.g., working hours, years of employment, and work environment) and the relatively small size for certain job type constrained our capability to further probe into possible mechanisms. For example, owing to the limited number of youths working full-time in this sample ( $n=48$ and $0.8 \%$ ), we were only allowed to examine work intensity as a categorical covariate (e.g., full-time or part-time), rather than to evaluate possible effects of working hours on drug involvement.
Finally, the nature of observational data, with a cross-sectional and retrospective design, might limit casual inferences of this study. It is plausible that there might be bi-directional relationships operating between employment and drug-using behaviors. For instance, in order to attain the economic resources to purchase alcohol, tobacco, or betel nut, drug-using youth might be more likely to enter or stay in the labor force. Future longitudinal research with exhaustive data on youth's drug experience, employment history, income or allowance, market prices of alcohol, tobacco, and betel nut will be of great help in disentangling such complex and reciprocal relationships between youthful employment and drug involvement.

Notwithstanding limitations such as these, a distinguishing feature of our study is that the outreach program might assess drug-related experience of youth who would be otherwise not recruited in school- or household-based surveys (e.g., school drop-outs, homeless) (Johnson, 2004; Kouvonen and Lintonen, 2002; Safron et al., 2001; Valois et al., 1999; Wakai et al., 2005). In addition, samples were drawn from seven regions of the country in an attempt to capture possible regional differences, as well as to provide adequate sample size and statistical power. 
Consistent with prior research (Johnson, 2004; Kouvonen and Lintonen, 2002; Mortimer et al., 1996; Paschall et al., 2002, 2004; Valois et al., 1999; Wu et al., 2003), the results of the current study suggest that working youths, with the exception for those employed in educational settings, were more likely to engage in drug-using behaviors. Indeed, due to deficiency in mature coping skills, the employed youngsters may start or increase use of psychoactive drugs to alleviate stress derived from unsatisfactory job conditions or demanding workload (Frone and Windle, 1997; Wills, 1986). In addition, even though the youth's employment status was correlated with his/her background characteristics and individual bonds with family and school, employment-related excess odds for drug experiences was still observed, with the strongest association found in polydrug use, followed by tobacco and alcohol. These possible drug-related differences observed in association estimates may, to certain extent, reflect different cultural meanings, social norms, and availability for drugs under study. For example, alcoholic beverages have been usually considered as a food or medicine rather than a psychoactive substance in Taiwan. Many youth might have had their first alcoholic beverage at a family-oriented occasion, and parents, in general, seem more tolerable of children's alcohol drinking than their tobacco smoking or betel nut chewing.

Previous research suggests that employment-associated risks for developmental and health problems were more salient for those who had longer work hours or higher work intensity (Mortimer et al., 1996; Wu et al., 2003), our findings for such links were only shown for polydrug use. The absence of such work intensity-related gradient in the association estimates between employment and alcohol or tobacco-using behaviors may suggest possible etiological heterogeneity between single and polydrug users. However, it could be argued that the observation may just reflect the issues of imprecision or selection bias, due to a smaller size of full-time workers recruited via the outreach program.

In the present research, employed smokers were found to have an older age for first tobacco use as compared to their unemployed smoking counterparts. Several explanations may account for these employed-related differences in the onset age of cigarette smoking. For example, the employed youth might just have had their first use of tobacco subsequent to their engagement in the labor force during summer recess prior to the time of assessment. However, it is also possible that smokers with earlier age of onset, who were most likely to be found among heavy smokers or illegal drugs users, were less likely to seek job opportunity or to stay in the labor force. Interestingly, youthful experiences of the three most commonly consumed substances in Taiwan seem not homogeneous across different job types, suggesting that differential exposure opportunity or accessibility may play a role in working youth's risk to initiate or maintain their alcohol- or tobacco-using behaviors. This observation may have some additional preventive implications - that is, in addition to school- or community-based programs, work-sites may be considered as an important channel to prevent or reduce adolescent psychoactive drug involvement, especially for those with older ages or lower socioeconomic status.
"Not attending school" appears to be a salient factor predicting recent drug-using behaviors, especially for tobacco and polydrug use. This observation may, in part, relate to that adolescents without school attendance, such as school dropouts, usually bear a lower social control exerted by school, and have more time wandering around settings where drug are easily and commonly available. Indeed, this school-related social control may be the explanation accounting for the observed lower rates of alcohol, tobacco, betel nut, and polydrug use for youths working in educational settings. It is noted that unfavorable effects of "not living with family" were not evident for youthful drug involvement in this study. "Not living with family" was initially designed as a proxy to assess family bond as well as parental control; however, since the reasons for most youngsters who did not live with their family were the consequences of attending schools outside his/her residential school district, this measure, therefore, may not faithfully reflect the level of family bond. Similar to the work by Soteriades and DiFranza (2003), we found youths with more disposable allowance were less likely to be in the labor force, but were more likely to engage in drug-related behaviors. The possible explanations for this observation are that youths with more disposable allowance may (i) be able to afford or maintain substance use, or (ii) have more opportunities to be involved in occasions or activities where alcohol or tobacco are widely available (e.g., internet café, pub).

In summary, the results of this study found that adolescent employment may be associated with a greater involvement of alcohol, tobacco, betel nut, and polydrug use in Taiwan. Future research may be needed to delineate the mechanisms exacerbating working youth's drug problems. Given that youth population persistently grows in Taiwan's labor force (Yi, 2005), prevention programs or health policies may consider focusing on this high-risk group to reduce possible drug-related negative consequences in developmental and health domains. For example, programs such as pre-job training consultation, and interventional policy or regulations at certain workplace (e.g., smokefree restaurants may be necessary to be developmentally tailored to match the needs of this vulnerable group (Farkas et al., 2000; Hunt et al., 2003; Stoddard et al., 2005).

\section{Acknowledgements}

This work was supported by grants from the Department of Health, Taiwan (DOH92-NNB-1008 and DOH93-NNB-1012). The authors wish to thank Dr. Carla L. Storr at Johns Hopkins University for valuable comments to an earlier version of this paper.

\section{References}

Bachman, J.G., Schulenberg, J., 1993. How part-time work intensity relates to drug use, problem behavior, time use, and satisfaction among high school seniors: are these consequences or merely correlates? Dev. Psychol. 29, 220-235.

Chen, C.Y., Dormitzer, C.M., Gutierrez, U., Vittetoe, K., Gonzalez, G.B., Anthony, J.C., 2004. The adolescent behavioral repertoire as a context for drug exposure: behavioral autarcesis at play. Addiction 99, 897-906. 
Chou, L.C., Ho, C.Y., Chen, C.Y., Chen, W.J., 2006. Truancy and illicit drug use among adolescents surveyed via street outreach. Addict. Behav. 31, $149-154$.

Chu, N.S., 2001. Effects of betel chewing on the central and autonomic nervous systems. J. Biomed. Sci. 8, 229-236.

Farkas, A.J., Gilpin, E.A., White, M.M., Pierce, J.P., 2000. Association between household and workplace smoking restrictions and adolescent smoking. JAMA 284, 717-722

Finch, M.D., Mortimer, J.T., Ryu, S., 1997. Transition into part-time work: health risks and opportunities. In: Schulenberg, J., Maggs, J.L., Hurrelmann, K. (Eds.), Health Risks and Developmental Transitions during Adolescence. Cambridge University Press, New York, NY, pp. 321343.

Frone, M.R., Windle, M., 1997. Job dissatisfaction and substance use among employed high school students: the moderating influence of active and avoidant coping styles. Subst. Use Misuse 32, 571-585.

Hsu, C.C., Levy, D.T., Wen, C.P., Cheng, T.Y., Tsai, S.P., Chen, T., Eriksen, M.P., Shu, C.C., 2005. The effect of the market opening on trends in smoking rates in Taiwan. Health Policy 74, 69-76.

Hunt, M.K., Fagan, P., Lederman, R., Stoddard, A., Frazier, L., Girod, K., Sorensen, G., 2003. Feasibility of implementing intervention methods in an adolescent worksite tobacco control study. Tob. Control 12 (S), 40-45.

Johnson, M.K., 2004. Further evidence on adolescent employment and substance use: differences by race and ethnicity. J. Health Soc. Behav. 45, 187-197.

Kouvonen, A., Lintonen, T., 2002. Adolescent part-time work and heavy drinking in Finland. Addiction 7, 311-318.

McMorris, B.J., Uggen, C., 2000. Alcohol and employment in the transition to adulthood. J. Health Soc. Behav. 41, 276-294.

Mortimer, J.T., Finch, M.D., Ryu, S., Shanahan, M.J., Call, K.T., 1996. The effects of work intensity on adolescent mental health, achievement, and behavioral adjustment: new evidence from a prospective study. Child Dev. 67, 1243-1261.

National Statistics, 2005. Labor Force Participation Rate by Age in Taiwan Area. http://www.stat.gov.tw/public/data/dgbas03/bs7/yearbook/ch3/3-6.xls\#a2 (accessed July 2005).

Osgood, D.W., Wilson, J.K., O’Malley, P.M., Bachman, J.G., Johnston, L.D., 1996. Routine activities and individual deviant behavior. Am. J. Sociol. 61, 635-655.

Paschall, M.J., Flewelling, R.L., Russell, T., 2004. Why is work intensity associated with heavy alcohol use among adolescents? J. Adolesc. Health 34, $79-87$.
Paschall, M.J., Ringwalt, C.L., Flewelling, R.L., 2002. Explaining higher levels of alcohol use among working adolescents: an analysis of potential explanatory variables. J. Stud. Alcohol 63, 169-178.

Safron, D.J., Schulenberg, J.E., Bachman, J.G., 2001. Part-time work and hurried adolescence: the links among work intensity, social activities, health behaviors, and substance use. J. Health Soc. Behav. 42, 425-449.

Sanford, M., Offord, D., McLeod, K., Boyle, M., Byrne, C., Hall, B., 1994 Pathways into the work force: antecedents of school and work force status. J. Am. Acad. Child Adolesc. Psychiatry 33, 1036-1046.

Soteriades, E.S., DiFranza, J.R., 2003. Parent's socioeconomic status, adolescents' disposable income, and adolescents' smoking status in Massachusetts. Am. J. Public Health 93, 1155-1160.

StataCorp, 2003. STATA Statistical Software. Release 8.0. College Station, Stata Corporation, TX.

Stoddard, A.M., Fagan, P., Sorensen, G., Hunt, M.K., Frazier, L., Girod, K., 2005. Reducing cigarette smoking among working adolescents: results from the SMART study. Cancer Causes Control 16, 1159-1164.

Tsai, Y.F., Wong, T.K., Chen, S.C., 2002. Prevalence and related risk factors of areca quid chewing among junior high students in eastern Taiwan. Public Health 116, 190-194.

Valois, R.F., Dunham, A.C., Jackson, K.L., Waller, J., 1999. Association between employment and substance abuse behaviors among public high school adolescents. J. Adolesc. Health 25, 256-263.

Wakai, K., Miura, H., Umenai, T., 2005. Effect of working status on tobacco, alcohol, and drug use among adolescents in urban area of Thailand. Addict. Behav. 30, 457-464

Wang, Y.C., Lee, C.M., Lew-Ting, C.Y., Hsiao, C.K., Chen, D.R., Chen, W.J., 2005. Survey of substance use among high school students in Taipei: web-based questionnaire versus paper-and-pencil questionnaire. J. Adolesc. Health 37, 289-295.

Wen, C.P., Levy, D.T., Cheng, T.Y., Hsu, C.C., Tsai, S.P., 2005a. Smoking behaviour in Taiwan, 2001. Tob. Control 14 (S1), i51-i55.

Wen, C.P., Tsai, S.P., Cheng, T.Y., Chen, C.J., Levy, D.T., Yang, H.J., Eriksen, M.P., 2005b. Uncovering the relation between betel quid chewing and cigarette smoking in Taiwan. Tob. Control 14 (S1), i16-i22.

Wills, T.A., 1986. Stress and coping in early adolescence: relationships to substance use in urban school samples. Health Psychol. 5, 503-529.

Wu, L.T., Schlenger, W.E., Galvin, D.M., 2003. The relationship between employment and substance use among students aged 12-17. J. Adolesc. Health 32, 5-15.

Yi, C.C., 2005. Taiwan Youth Project. http://www.typ.sinica.edu.tw/modules/ mydownloads/viewcat.php?cid=4/ (accessed 7 April 2005) 